\title{
Application of a CdTe Gamma-Ray Spectrometer to Remote Characterization of High-Level Radioactive Waste Tanks
}

\author{
R. S. Addleman \\ G. R. Blewett \\ B. D. Keele \\ C. S. McClellan \\ V. B. Subrahmanyam \\ G. L. Troyer
}

Date Published

April 1993

To Be Published in IEEE Transactions on Nuclear Science

Prepared for the U.S. Department of Energy Office of Environmental Restoration and Waste Management

\section{(28) Westinghouse Hanford Company Richland, Washington 99352}

Hanford Operations and Engineering Contractor for the

U.S. Department of Energy under Contract DE-AC06-87RL10930

Copyright License By acceptance of this article, the publisher and/or recipient acknowledges the U.S. Government's right to retain a nonexclusive, royatty-tree license in and to any copyright covering this paper. 


\section{DISCLAIMER}

This report was prepared as an account of work sponsored by an agency of the United States Government. Neither the United States Government nor any agency thereof, nor any of their employees, make any warranty, express or implied, or assumes any legal liability or responsibility for the accuracy, completeness, or usefulness of any information, apparatus, product, or process disclosed, or represents that its use would not infringe privately owned rights. Reference herein to any specific commercial product, process, or service by trade name, trademark, manufacturer, or otherwise does not necessarily constitute or imply its endorsement, recommendation, or favoring by the United States Government or any agency thereof. The views and opinions of authors expressed herein do not necessarily state or reflect those of the United States Government or any agency thereof. 


\section{DISCLAIMER}

Portions of this document may be illegible in electronic image products. Images are produced from the best available original document. 


\title{
Application of a CdTe Gamma-Ray Spectrometer to Remote Characterization of High-Level Radioactive Waste Tanks*
}

\author{
R. S. Addleman \\ G. R. Blewett \\ B. D. Keele \\ C. S. McClellan \\ V. B. Subrahmanyam \\ G. L. Troyer
}

Westinghouse Hanford Company, Richland, WA 99352

\begin{abstract}
Small, shielded cadmium telluride (CdTe) semiconductor gamma-ray detectors have been used for in situ radiological characterization of underground high-level radioactive waste tanks. Remote measurements have been made in gamma radiation fields up to $700 \mathrm{R} / \mathrm{h}$. Spectral data have been used to generate qualitative and quantitative radionuclide profiles of high-level radioactive waste tanks.

Two electronic spectral enhancement techniques (pulse risetime discrimination and pulse risetime compensation) have been used in order to measure trace isotopes with photopeak energies greater than $662 \mathrm{keV}$ in the presence of large amounts of ${ }^{137} \mathrm{Cs}$. Spectral resolution of $1.5 \%$ FWHM for the ${ }^{137} \mathrm{Cs} 662 \mathrm{keV}$ photopeak has been obtained.
\end{abstract}

\section{INTRODUCTION}

A large portion of the nations high-level radioactive waste is stored at the Hanford Site in large underground storage tanks. Characterization of high-level waste tank (HLWT) contents is one of the first steps toward the cleanup of the tanks and the environmental restoration of the Hanford Site.

Radionuclide content and distribution in HLWTs have been determined by in situ CdTe gamma-ray spectroscopy. The predominate gamma-ray emitter in the HLWTs is ${ }^{137} \mathrm{Cs}$. The large abundance of ${ }^{137} \mathrm{Cs}$ makes measurements of other isotopes with photon energies below $662 \mathrm{keV}$ impossible. Measurements of higher energy gamma rays, ${ }^{60} \mathrm{Co},{ }^{152} \mathrm{Eu}$, and ${ }^{154} \mathrm{Eu}$ have been successful.
Measurement access is limited to penetrating drywells (typically $3 \mathrm{in}$. in diameter) located on the interior and exterior of the HLWTs. Probes containing the detector, shielding, preamplifier, and an auxiliary cooling system have been constructed to fit within the drywells. Gamma radiation fields within the HLWTs can reach $700 \mathrm{R} / \mathrm{h}$.

Small, $2 \times 2 \times 2 \mathrm{~mm}$, planar configuration cadmium telluride (CdTe) detectors manufactured by Radiation Monitoring Devices, Inc. were used for this application. CdTe's high atomic number provides significant stopping power and good peak-to-total ratio for small detectors.

The traditional problem of charge trapping with $\mathrm{CdTe}$ detectors has been partially overcome by incorporation of two spectral enhancement techniques. With the pulse risetime discrimination (PRD) technique, a large fraction of events are rejected based on risetime in a manner similar to references 1 and 2. Pulse risetime compensation (PRC) is an event amplitude correction technique based on the risetime of the event. References 3 and 4 describe the use of this technique with germanium detectors.

\section{DETECTOR AND ELECTRONIC CONFIGURATION}

\section{A. Pulse Risetime Discrimination}

The PRD was used as a method to electronically enhance photopeak resolution. At the preamplifier output, the risetime of each event (pulse) occurring within the detector is determined. Pulses that lie within a narrow range of risetimes are accepted for counting, and the remainder of the pulses are rejected. Approximately half of the events are rejected.

*Performed under DOE Contract DE-AC06-87 RL10930. 
The electronic configuration for the PRD system is shown in Fig. 1. The pulse risetime analysis system consists of a single delay-line amplifier, a pulse-shape analyzer, and a time-to-amplitude converter with an integral single-channel analyzer (SCA). The pulse-shape analyzer functions in the same manner as two constant fraction discriminators. This provides a risetime spectrum which is independent of the gamma-ray energy region utilized.

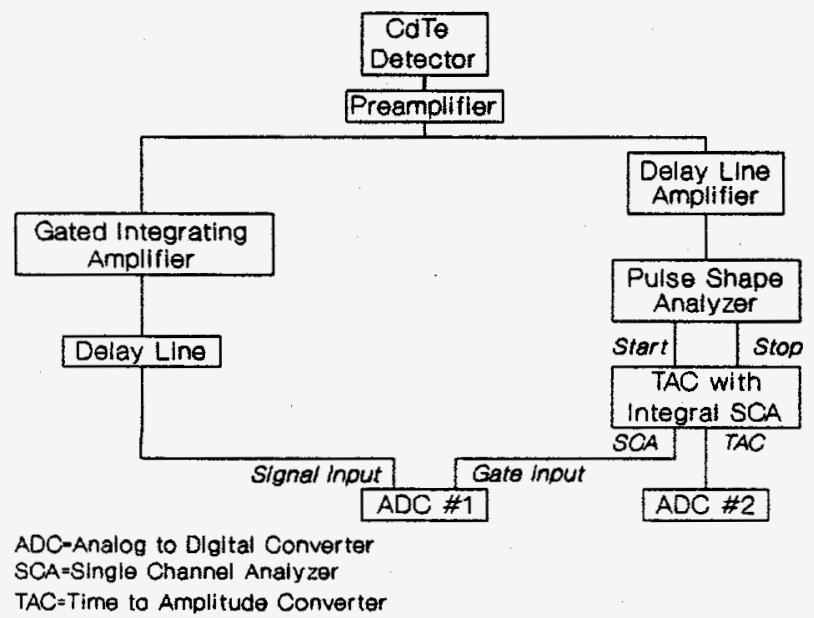

Fig. 1 PRD block electronics

Fig. 2 represents a typical risetime distribution of preamplifier output pulses. Pulses within the highlighted range of risetimes were accepted for counting, the remainder were rejected.

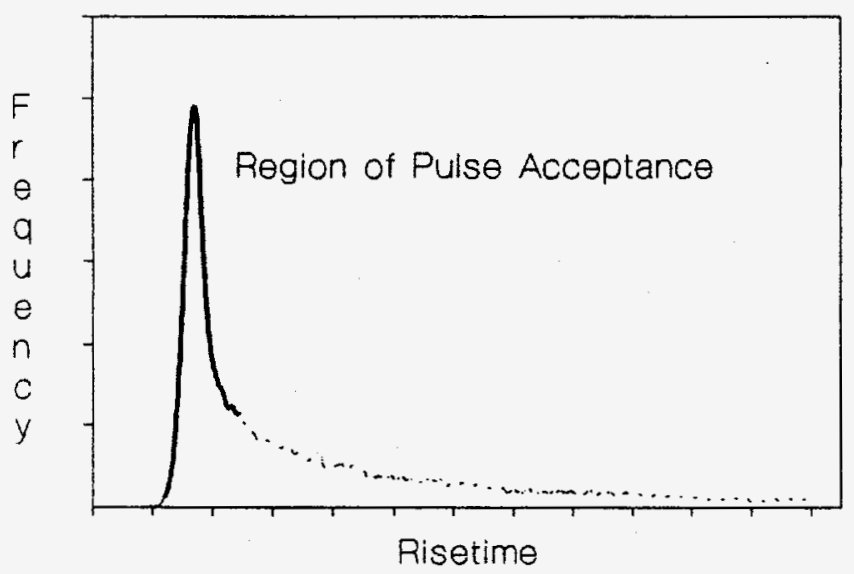

Fig. 2 CdTe pulse risetime spectrum

Fig. 3 displays a gamma-ray energy spectrum with a $2 \times 2 \times 2 \mathrm{~mm}$ CdTe detector taken with and without PRD. The unenhanced spectrum is a composite gamma-ray energy spectrum with events from all risetimes. Fig. 3 also gives a spectrum with PRC. It was found that pulses of any selected risetime produced quality gamma-ray energy spectra as illustrated in Fig. 4. Slower rising events generate photopeaks which are shifted to lower channels than faster rising events. Spectra are reproducible at different shaping times thus; the effect is due to charge trapping and not ballistic deficit. During slower rising events, charge is resident within the crystal for longer periods of time; the holes and electrons have a greater probability to recombine or become trapped. This leads to lower amounts of charge collection, which describes the photopeak shifts observed. Region 1 was chosen to derive the spectrum from because the signals within it offered the best comprise between and spectral resolution and system efficiency.

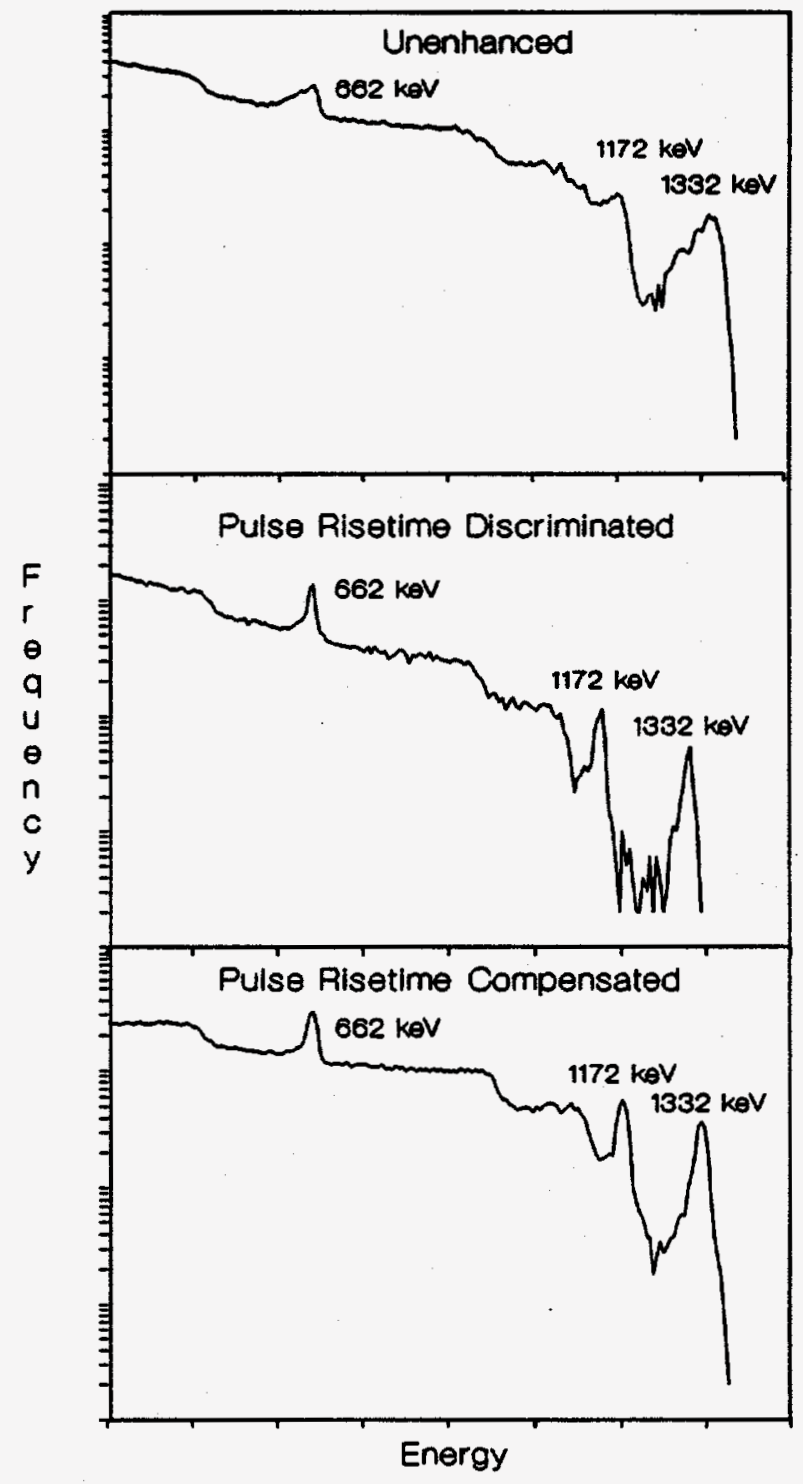

Fig. 3 Effect of enhancement techniques 


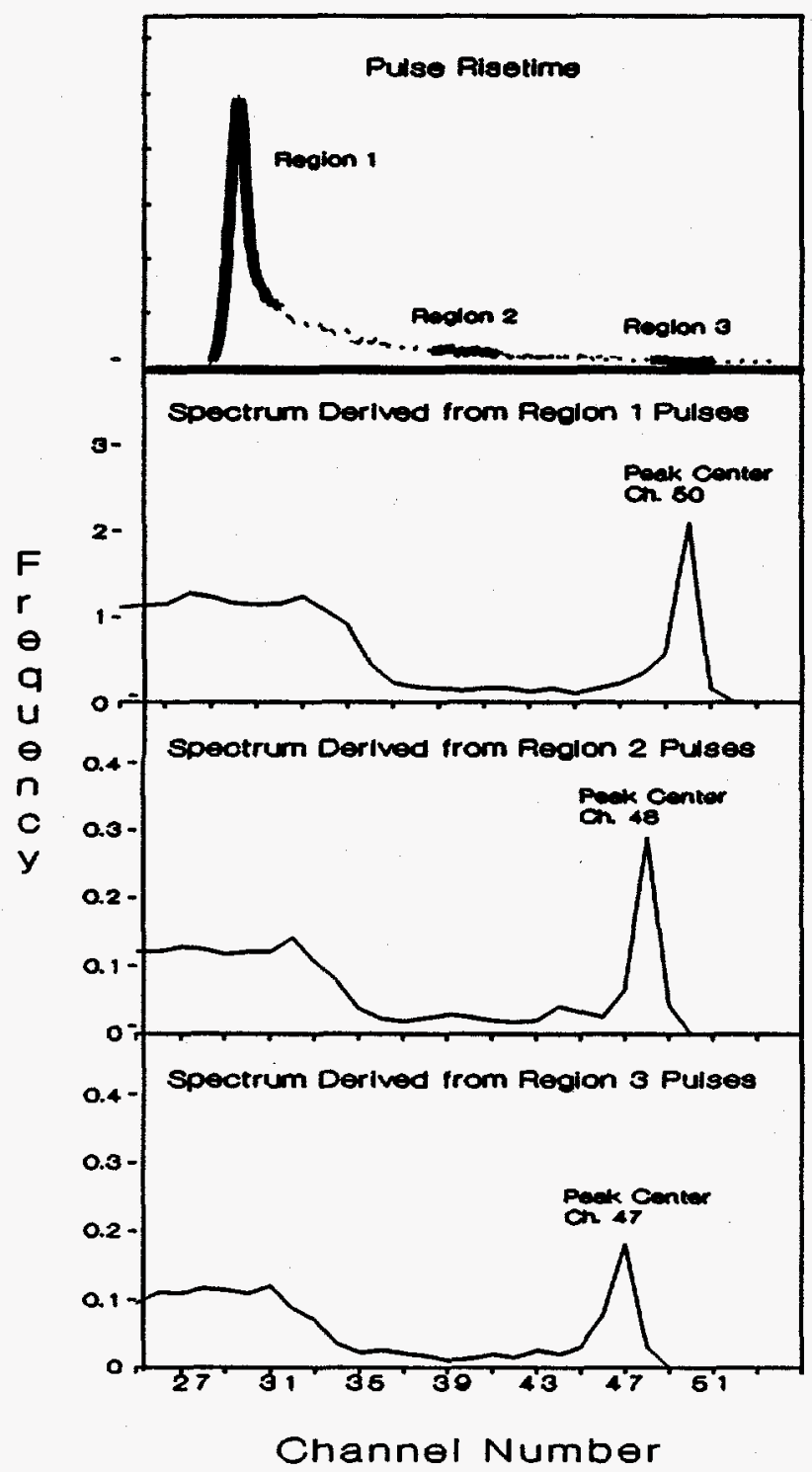

Fig. 4 The effect of risetime on a ${ }^{137} \mathrm{Cs}$ gamma-ray energy spectrum

By selecting a specific risetime, spectral resolution can be improved at the expense of detector efficiency. Using a PRD, a resolution of $1.5 \%$ full width at half maximum (FWHM) for ${ }^{137} \mathrm{Cs}$ was obtained.

A gated integrating amplifier with a shaping time constant of $0.25 \mu \mathrm{sec}$ was used because of the high radiation fields encountered. The gated integrator was used to overcome a ballistic deficit resulting from short shaping times. The PRD effectively performs pulse pile up rejection.

\section{B. Pulse Risetime Compensation}

The PRC technique adjusts the amplitude of the pulse by an amount proportional to the square of the risetime of the event. This is performed with an analog computer that was developed to correct for ballistic deficits in germanium detectors and to correct for charge trapping in neutron damaged germanium detectors. The computer is commercially available from EG\&G ORTEC, and is called a germanium resolution enhancer. This technique counts every event while maintaining satisfactory resolution.

The electronic configuration for the PRC system is diagrammed in Fig. 5. This system consists of a gated integrator which provides the spectral signal, a spectroscopy amplifier from which the risetime is derived, and the resolution enhancer.

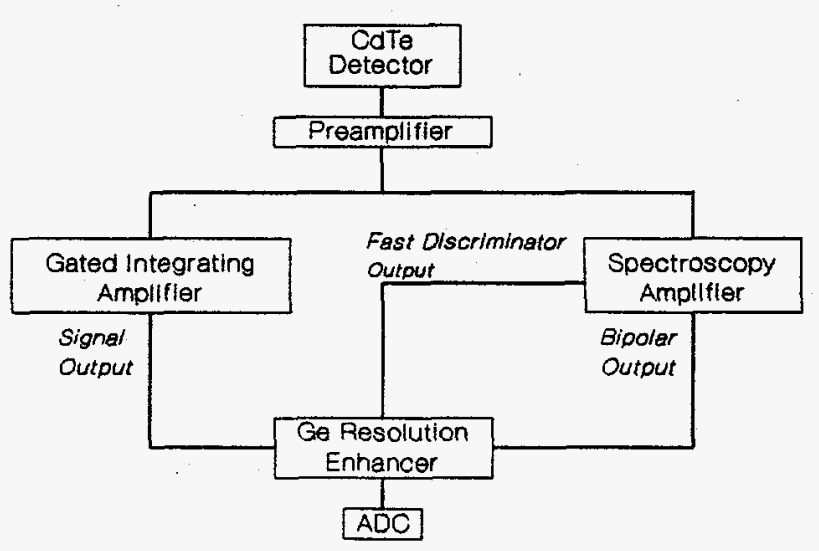

Fig. 5 PRC block diagram

In theory, the germanium resolution enhancer should correct for both ballistic deficit and charge trapping within the CdTe crystal. In practice, spectral quality is improved by using the gated integrator to overcome the ballistic deficit and by using the resolution enhancer to overcome charge trapping. Fig. 3 contains gamma-ray energy spectra taken of a ${ }^{137} \mathrm{Cs}$ and ${ }^{60} \mathrm{Co}$ source using the PRC system. Using the PRC system, photopeak resolution of $2.5 \%$ FWHM at $662 \mathrm{keV}$ was achieved while counting every event.

\section{Detector Temperature and Bias Voltage Dependency}

The maximum manufacturer recommended operating temperature for the detector was $48{ }^{\circ} \mathrm{C}$. It was noted that operation above $32{ }^{\circ} \mathrm{C}$ would produce gain shifts as well as broadening of the pulse risetime spectra. Because the internal temperatures of some HLWTs were over $80^{\circ} \mathrm{C}$, the detector was cooled with circulating ice water.

Varying the detector bias changed the shape of the risetime distribution as shown in Fig. 6. When the detector was biased below $100 \mathrm{~V}$, the risetime distribution was unstable and subject to large drifts in both peak position and shape. Photopeak quality can be seen to improve with bias voltage in Fig. 7. The detector has been routinely operated at $200 \mathrm{~V}$ for extended periods of time. 


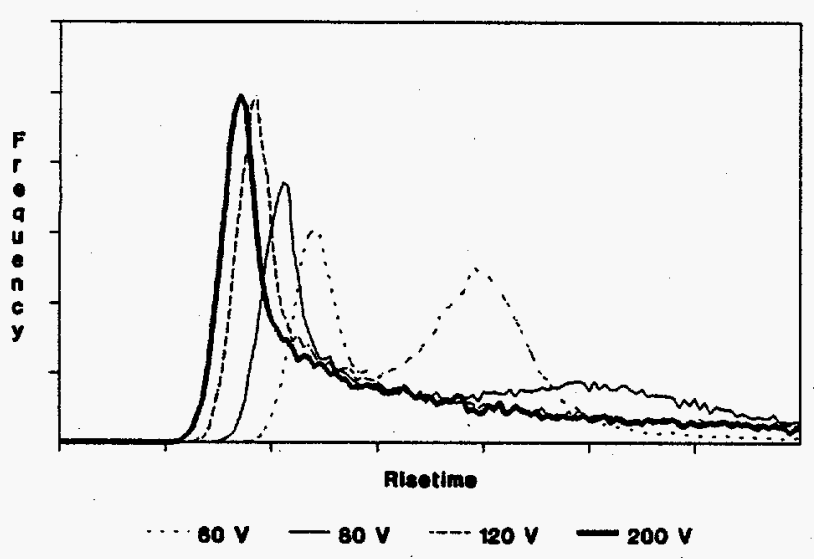

Fig. 6 The effect of bias voltage on the risetime

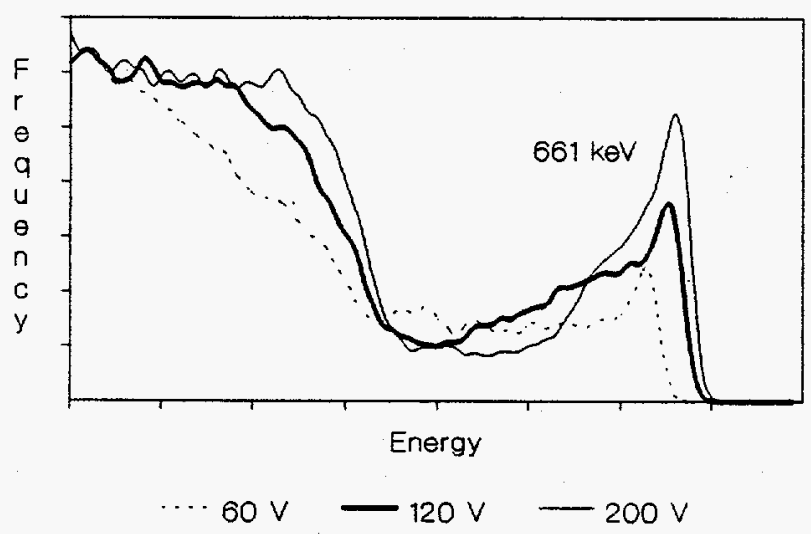

Fig. 7 The effect of voltage on an unenhanced ${ }^{137} \mathrm{Cs}$ gamma-ray energy spectrum

\section{RESULTS AND DISCUSSION}

Spectral resolutions of $1.5 \%$ and $2.5 \%$ FWHM @ $662 \mathrm{keV}$ have been obtained using PRD and PRC. This resolution is better than sodium iodide scintillators but not as good as germanium or silicon semiconductor detectors. Because of the high atomic number of CdTe, the peak-tototal ratio is a factor of 10 better than an equivalent sized germanium detector.

The electronic enhancement techniques, PRD, and PRC have been successful in compensating for problems associated with charge mobility and charge trapping. The PRD selects events with uniform charge trapping based on selecting events with similar risetimes. The PRD results in the best resolution at the expense of rejecting many events. The PRC compensates for charge trapping by adjusting the signal based on the square of the risetime. The PRC also results in good energy resolution while counting all events.
Of the two electronic techniques PRC is significantly more efficient since it count all pulses and PRD, depending on the spectral resolution desired, discards $30-60 \%$ of the signals. However, discarding the undesirable signals allows PRD to have function in higher radiation fields and produce better spectral resolution than PRC.

Performance and stability of CdTe detectors were observed to significantly improve at higher bias voltages.

CdTe detectors, with electronic enhancements, have proven useful for application in gamma-ray spectroscopy within confined spaces with high radiation fields. The specific advantages of $\mathrm{CdTe}$ are as follows:

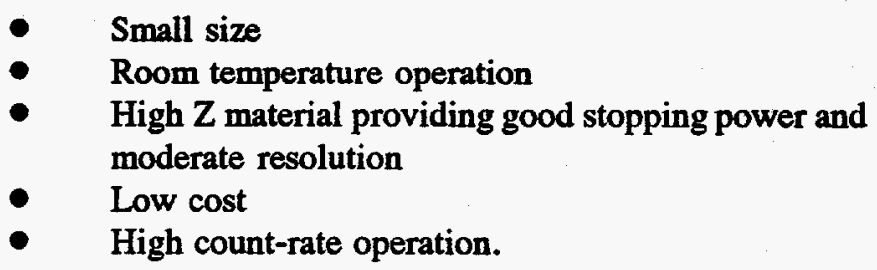

\section{FUTURE WORK}

Future improvements will include locating the origin of the timing signals at the preamplifier level, customizing the preamplifier to match the characteristics of CdTe more closely, and performing PRC digitally for improved resolution. Implementing these changes will probably improve the resolution available from CdTe systems. It appears that if a detector can be made such that higher bias voltages can be successfully applied, no enhancement electronics will be necessary.

\section{ACKNOWLEDGEMENTS}

We would like to thank W. K. Hensley of Pacific Northwest Laboratory for his advice that led to the present work.

\section{REFERENCES}

[1] L. T. Jones and P. B. Woollam, "Resolution Improvement in CdTe Gamma Detectors Using Pulse-Shape Discrimination," Nuclear Instruments and Methods, vol. 124, pp. 591-595, 1975.

[2] L. T. Jones, "The Use of Cadmium Telluride Gamma Spectrometers in Monitoring Activity Deposited in Nuclear Power Stations," Revue De Physique Appliquee, Vol. 12, No. 2, pp. 379-384, Feb. 1977.

[3] F. S. Goulding and D. A. Landis, "Ballistic Deficit Correction in Semiconductor Detector Spectrometers," IEEE Transactions on Nuclear Science, Vol. 35, No. 1, pp. 119-124, Feb. 1988. 
[4] M. L. Simpson, T. W. Raudorf, T. J. Paulus, and R. C. Trammel, "Charge Trapping Correction in Ge Spectrometers," IEEE Transactions on Nuclear Science, Vol. 36, No. 1, Feb. 1989. 
WHC-1196-SA-FP

\section{DISTRIBUTION}

Number of copies

ONSITE

U.S. Department of Energy-

Richland Operations Office

R. F. Christensen

E6-33

21

Westinghouse Hanford Company

R. S. Addleman (2) T6-50

G. R. Blewett (2)

T6-31

B. D. Keele (8)

T6-31

C. S. McClellan (2)

S0-61

V. B. Subrahmanyam (2)

T6-31

G. L. Troyer (2)

T6-50

Information Release

Administration (2)

L8-07

Document Processing and

Distribution

L8-15 